\title{
THERMAL DECOMPOSITION KINETICS OF POTATO POWDER
}

\author{
LI, P. H. - LIN, Q. ${ }^{*}$ LIN, L. - LIU, H. - ZHANG, Z. \\ Xichang University, Xichang 61500, China \\ *Corresponding author \\ e-mail: 13778672269@qq.com; phone: +86-137-7867-2269 \\ (Received $3^{\text {rd }}$ Apr 2019; accepted $17^{\text {th }}$ May 2019)
}

\begin{abstract}
This paper studies the thermal decomposition kinetics of potato powder under static air atmosphere using a DTG-60 differential thermal-thermogravimetric analyzer, with an aim of exploring the thermal stability of potato powder under high temperature. The authors conducted condition experiments on the samples, optimized various parameters that affect thermal analysis and determined the appropriate test conditions. Then, the mechanism function that for the thermal decomposition kinetics study of potato powder was explored, and the powder's thermal decomposition kinetic parameters were calculated along with the kinetic equation using the Coats-Redfern method. The results show that the suitable test conditions for thermal decomposition of potato powder include a heating rate $\beta$ of $15^{\circ} \mathrm{C} / \mathrm{min}$ and a sample mass of $2.695 \mathrm{mg}$. The temperature is $559.18 \mathrm{~K}\left(286.03{ }^{\circ} \mathrm{C}\right)$ when the decomposition starts at the initial stage of reaction; the activation energy value is $\mathrm{E}=339.810 \mathrm{~kJ} / \mathrm{mol}$ and the pre-exponential factor $\mathrm{A}=\mathrm{e}^{75.32}$. The kinetic equation is $\frac{\mathrm{d} \alpha}{\mathrm{dt}}=\mathrm{e}^{75.32-\frac{332810}{8.314 \mathrm{~T}}}(1-\alpha)$.

Keywords: potato powder, thermal decomposition, differential thermal-thermogravimetric analysis, kinetics, thermal stability, the Coats-Redfern method

Abbreviations: $E$ : activation energy, $\mathrm{KJ} \cdot \mathrm{mol}^{-1} ; G(\alpha)$ : kinetics mode function; TGA curve: thermogravimetric analysis curve; DTA curve: differential thermal analysis curve; $K$ : thermokinetic temperature, unit in $\mathrm{K}$ (Kelvin); $\alpha$ : solid sample mass conversion rate; $T$ : temperature, $\mathrm{K} ; \beta$ : differential thermal analysis heating rate ${ }^{\circ} \mathrm{C} / \mathrm{min} ; f(\alpha)$ : reaction mechanism function; $R$ : ideal gas constant, $8.314 \mathrm{KJ} \mathrm{mol}^{-1}$; Exp: natural logarithm; $E_{0}$ : activation energy calculated by the FWO method, $\mathrm{KJ} \cdot \mathrm{mol}^{-1}$; $E_{s}$ : activation energy calculated by the Stava-Sestak method, $\mathrm{KJ}_{\bullet} \mathrm{mol}^{-1} ; t$ : time, unit: second
\end{abstract}

\section{Introduction}

Potato is one of the most common vegetables in our daily life. Not only does it have protein that is similar to animal protein (better than soy protein), but it also contains some macro and trace elements that are not found in some vegetables and fruits (Alonso et al., 2001; Zeng et al., 2015). Thanks to its rich nutrition, nice flavor and low price, potato has been very popular among the majority of families. In order to alleviate the current food shortage in China, research has been carried out actively in various places on potato as staple food (Bao et al., 2013; Kim et al., 2013), and a series of potato products have been developed, including potato cakes, noodles and buns (Chen, 2009; Zhang et al., 2013), which are very popular among consumers. Sichuan is a major potato producing province, with the total potato planting area ranking the fourth in China, and the total output ranking the first. In this province, Liangshan Prefecture is one of the main producing areas due to the great variety, excellent flavor and aftertaste of potatoes there (Huang et al., 2018). Liangshan Yi Autonomous Prefecture has now established standardized potato production bases, with four indicators - planting area, output, commodity volume and economic benefit ranking the first in the province, thus providing a good platform for potato research (Xie, 2014). 
The differential thermal analysis method is a test method that consumes only a small amount of samples, requires only simple operations and produces images which are easy to understand and analyze (Ike, 2018; Stenseng et al., 2001). It has been widely applied in the chemical industry to explore a series of physical, chemical or physicochemical changes in the heating process of samples (Zhao, 2005), such as weight loss, crystal structure changes, oxidation and thermal decomposition, etc., which has further promoted the development of the chemical industry. In recent years, through continuous improvement and correction by many researchers, the differential thermal analysis method has been gradually applied to other fields, showing its advantages such as short test time, simple operation and accurate results (Liu et al., 2013). If a sample and a reference material are heated at the same time, when the sample exhibits physical, chemical or physicochemical changes, the thermal effect will also change, resulting in a certain temperature difference between the sample and the reference material. This method, which determines the correlation between the sample-reference temperature difference and the time or temperature under the programmed temperature, is what we call the differential thermal analysis method.

The thermal decomposition kinetics study of potato powder by the differential thermal analysis method can help manufacturers better understand the thermodynamic properties of potato powder so that they can better utilize it during processing to increase its added value, improve the economic benefits of potatoes and thus drive the prosperous development of the potato industry in Liangshan and make relevant industries more standardized and internationalized (Fan et al., 2015).

\section{Materials and methods}

\section{Test materials}

The fresh potatoes were acquired from a produce market in Anning Town, Xichang City, Liangshan Prefecture, Sichuan Province.

\section{Instruments and conditions}

DTG-60 differential thermal-thermogravimetric analyzer (Fig. 1), produced by Shimadzu. The atmosphere condition for the test was static air; the reference material was an empty ceramic crucible; and the temperature rise range was $25 \sim 600{ }^{\circ} \mathrm{C}$.

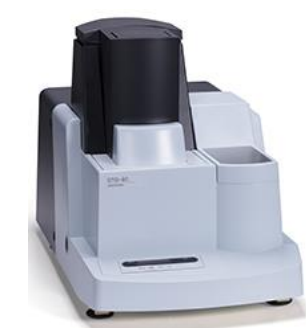

Figure 1. DTG-60 differential thermal-thermogravimetric analyzer

\section{Test methods}

In this test, according to the differential thermal analysis method, the atmospheric condition was set to be static air in the program, then the test conditions were changed 
by changing the heating rate or sample mass. In this way, different differential thermal analysis maps were obtained. Then the DTA curves obtained were analyzed and compared to determine the optimal test conditions for the potato powder thermal analysis. Under the optimal test conditions, the sample potato powder was subjected to thermal analysis and an image obtained, and then the image was subjected to thermogravimetric and differential thermal analysis. After analysis, calculation and collation of data, the activation energy value $E$ and the pre-exponential factor value A of the thermal decomposition reaction of potato powder were calculated using the CoatsRedfern integration method.

\section{(1) Preparation of materials}

The process flow is as follows:

Sampling $\rightarrow$ pre-treatment $\rightarrow$ pulping $\rightarrow$ filtering $\rightarrow$ drying $\rightarrow$ grinding $\rightarrow$ sieving ( 80 meshes)

The moisture content of the dried potato sample was controlled to $13.5 \%$ or less. The determination of the moisture content was carried out by reference to GB 5009.3-2016.

\section{(2) Condition experiments}

The compatibility and thermal stability of the energetic materials can be reflected directly by the characteristic quantities in the thermal analysis such as the heat change $\Delta \mathrm{H}$, the initial temperature $\mathrm{T}_{0}$, the final temperature $\mathrm{T}_{\mathrm{e}}$, the peak temperature $\mathrm{T}_{\mathrm{p}}$ and the weight loss $\mathrm{M}_{1}$, etc. or the kinetic parameters further obtained from these quantities (Song and $\mathrm{Wu}, 2016$ ). The heating rate $\beta$ and the sample size $\mathrm{m}$ may both have some effects on these characteristic quantities, which adds a lot of uncertainty to the experiment. Therefore, it is necessary to analyze the DTA curve, including the peak time, shape and smoothness, so as to obtain the optimal thermal analysis conditions for potato powder. In this experiment, two groups of single-factor tests were designed, to measure the effects of different masses (6 different masses) and of different heating rates (4 different heating rates) on the DTA curve of potato powder.

\section{(3) Determination of the kinetic equation}

Obtain a complete and smooth thermogram of the peak through the single-factor test. Measure the weight loss rate under each temperature range through the thermogravimetric curve, and then select the appropriate mechanism function $G(\alpha)$. Based on the straight line relationship of $\ln \left[\frac{\mathrm{G}(\alpha)}{T^{2}}\right]$ with $\frac{1}{T}$, find the linear regression equation of the curve with a good linearity ( $\mathrm{R}^{2}$ is the closest to 1$)$, and then calculate the activation energy $\mathrm{E}$ and the pre-exponential factor $\mathrm{A}$ which are closest to the true values using the slope and intercept of the linear regression equation (Ghaly et al., 2005).

\section{Results and discussion}

\section{Effects of different thermal analysis conditions on the thermal decomposition of potato powder}

The results obtained by differential thermal analysis are usually affected by the physical and chemical properties of the material being tested, the precision of the instrument, the samples used and the test conditions, among which, the conditions for thermal analysis have significant effects on the obtained thermogram. In this 
experiment, two groups of single-factor tests were carried out in the static air atmosphere, aiming to explore the effects of different sample masses and heating rates on the peak of the thermogram.

\section{(1) Effects of sample mass on the thermal decomposition process of potato powder}

For some energetic materials, the mass of a sample has little or no effect on the characteristic quantities of thermal decomposition temperature, but for others, it does on certain characteristic quantities. To investigate the effect of sample mass on the thermal decomposition image of potato powder, 6 tests were performed, with the sample mass changing in a gradient manner, as shown in Figure 2.

It can be seen from Figure 2 that there are two distinct endothermic peaks in the thermographic curves of potato powder with different masses. Under some heating rates, a small endothermic peak can be seen before the main reaction zone. The peaks generally show the same trend, indicative of the common thermal characteristics of potato powder. It is not hard to conclude that when the sample mass increases, the peak area will become larger and the error will increase due to the longer reaction time recorded by the instrument. It can be seen that when the mass of the test sample was $2.695 \mathrm{mg}$, the peak shown was better separated from those in the cases of other masses, and was sharp with a great intensity and a small area. Since DTG-60 is a highly sensitive instrument, if the sample size is too large, it will exceed the measuring range and contaminate the instrument. Therefore, the minimal sample mass that can be identified by DTG-60 should be used as long as it can ensure good separation effect, peak intensity and peak shape (Chen et al., 2001).

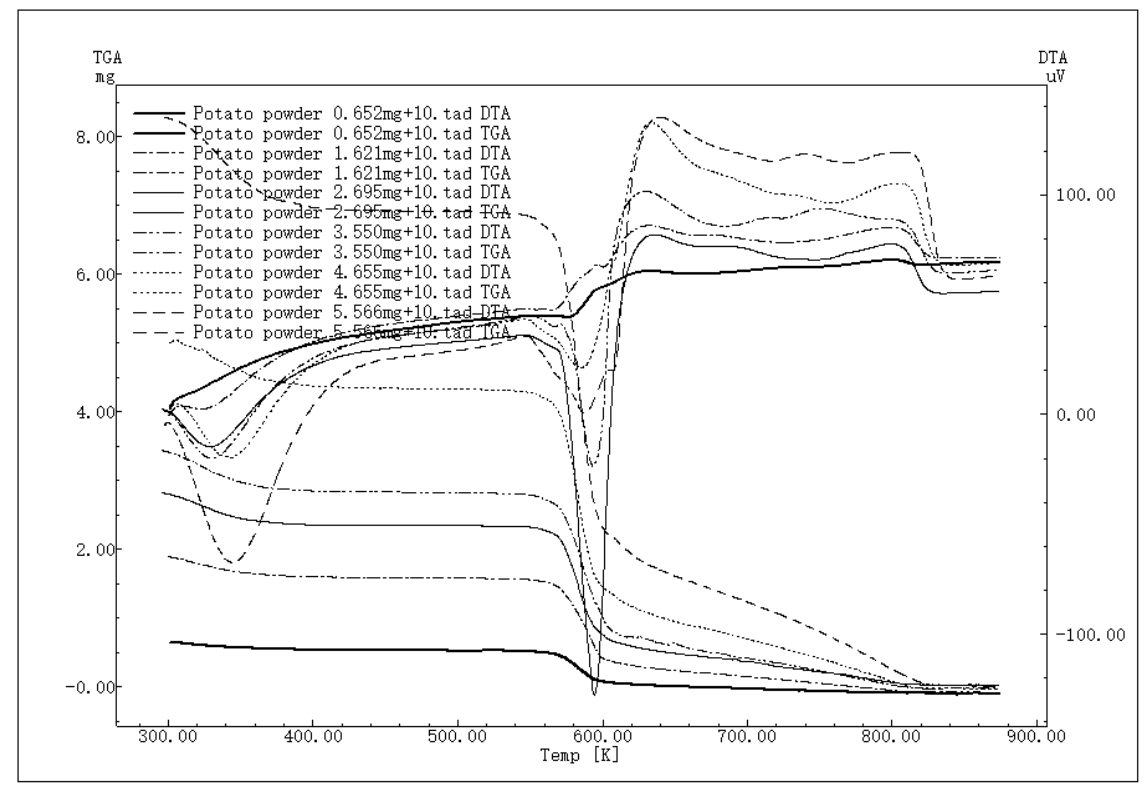

Figure 2. Differential thermal-thermogravimetric curve of potato powder with different masses

(2) Effects of temperature rise rate on the thermal decomposition process of potato powder

The effects of the heating rate $\beta$ on the characteristic quantities of thermal analysis are not only reflected in the changes in the peak area, but also in the position of the peak 
temperature. So the adoption of different heating rates $\beta$ can help understand and analyze the thermal behaviours of materials. This experiment designed four different heating rates $\beta$, namely $20^{\circ} \mathrm{C} / \mathrm{min}, 15^{\circ} \mathrm{C} / \mathrm{min}, 10^{\circ} \mathrm{C} / \mathrm{min}$ and $5{ }^{\circ} \mathrm{C} / \mathrm{min}$, respectively, so that the DTA curves of the potato powder under the four different heating rates were obtained as follows.

As can be seen from Figure 3, there is a large endothermic peak in all the thermographic curves of the potato powder, and all the peaks have basically the same characteristics. The differential thermal scan of each sample showed good reproducibility, indicative of the common thermal characteristics of potato powder. The faster the heating rate $\beta$ is, the shorter the reaction time of the sample will be recorded by the instrument DTG-60, the sharper the peak will become and the greater the distance will be between the decomposition and equilibrium conditions of the sample particles (Chakraborty, 2015), thus resulting in a baseline drift and making the two adjacent peaks overlapping. This will reduce the resolution and make the instrument less sensitive. On the contrary, the slower the heating rate $\beta$ is, the smaller the drift of the baseline will be, and the closer the system will get to the equilibrium conditions. In this way, the peak will be shallower and wider and can be better separated with the adjacent one, thus improving the resolution of the thermogram. However, it will take a longer time to determine the sample. In summary, the optimal heating rate obtained for this experiment is $15^{\circ} \mathrm{C} / \mathrm{min}$.

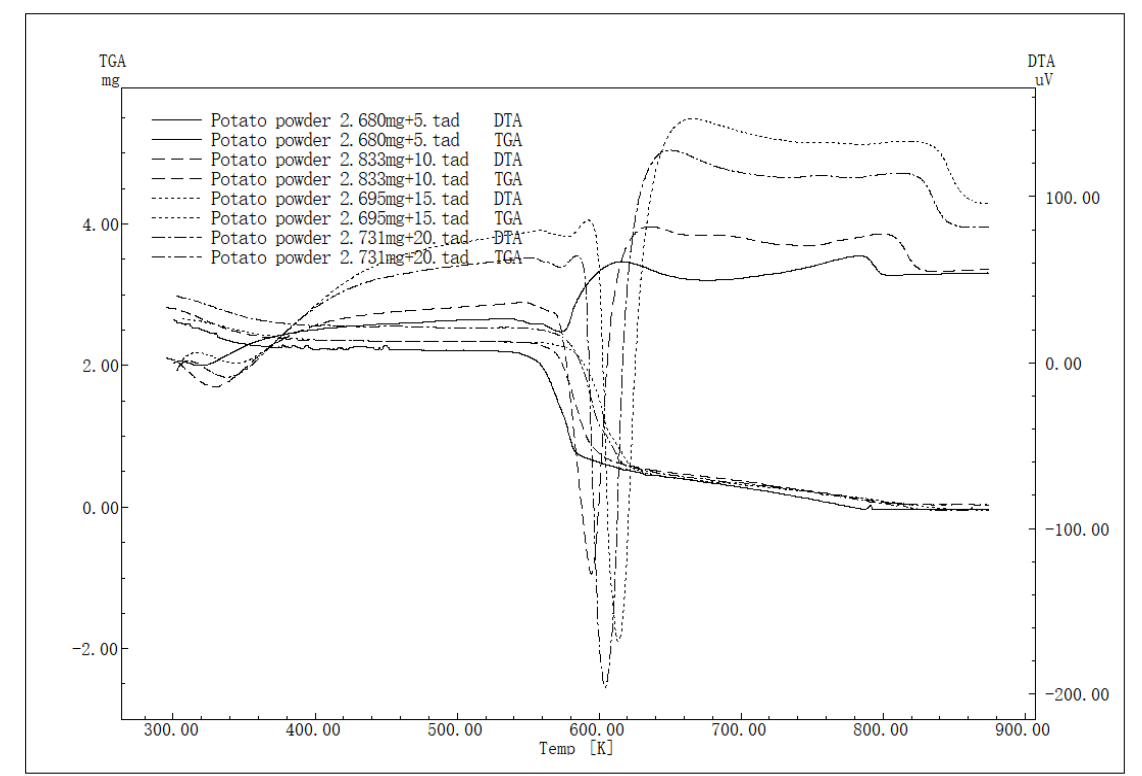

Figure 3. Differential thermal-thermogravimetric curve of potato powder under different heating rates

Through analysis the characteristic quantities in the thermogram, such as peak time, shape and smoothness, it can be concluded that the peak shape was the best when the sample mass was $2.695 \mathrm{mg}$ and the heating rate $15^{\circ} \mathrm{C} / \mathrm{min}$. The main peak was also sharp and smooth when the heating rate was $20^{\circ} \mathrm{C} / \mathrm{min}$, but the instrument was less sensitive as the heating rate was fast (Xu et al., 2017). In summary, when the sample mass was $2.695 \mathrm{mg}$ and the heating rate $15^{\circ} \mathrm{C} / \mathrm{min}$, the thermogram will be easier and more effective for thermal analysis. 


\section{Analysis of the thermal decomposition process of potato powder}

Through the above condition tests, it is found that the thermogram obtained was the best for thermal analysis when the sample mass was $2.695 \mathrm{mg}$ and the heating rate $15^{\circ} \mathrm{C} / \mathrm{min}$. This thermogram (Fig. 4) was then used in this research to investigate the thermal decomposition process of potato powder, calculate the kinetic parameters and determine the kinetic equation.

As can be seen from Figure 4, the thermal decomposition process of potato powder consists of four stages and produces a small amount of residual ash.

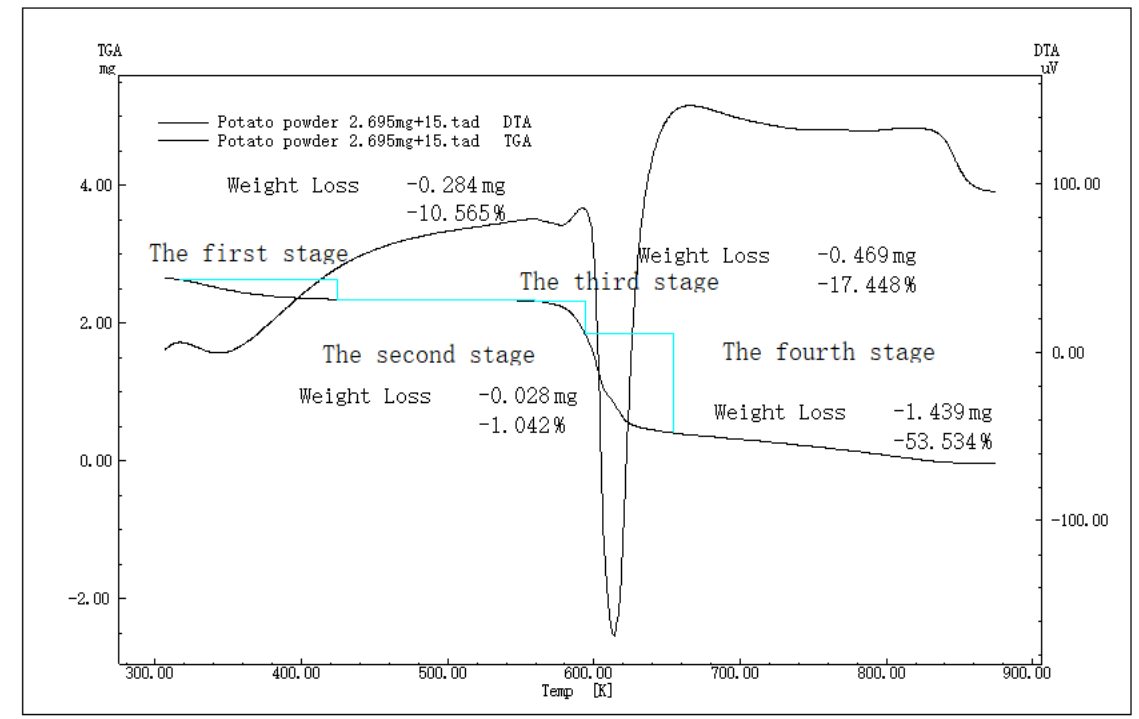

Figure 4. Optimal thermal analysis map

Stage 1 is $316.68 \sim 425.11 \mathrm{~K}\left(43.53 \sim 151.96^{\circ} \mathrm{C}\right)$. It is generally considered that the part before $400 \mathrm{~K}\left(128.55^{\circ} \mathrm{C}\right)$ is the water loss process, so Stage 1 is mainly the weight loss process (Wu et al., 2002).

Stage 2 is $425.11 \sim 559.18 \mathrm{~K}\left(151.96 \sim 286.03{ }^{\circ} \mathrm{C}\right)$. It is the transition stage of the thermal decomposition of potato powder, where the potato powder has stable properties, so it is the safe temperature range for food processing.

Stage 3 is $559.18 \sim 593.90 \mathrm{~K}\left(286.13 \sim 320.75^{\circ} \mathrm{C}\right)$. Part of the small molecule substances begin to undergo the thermal decomposition reaction, so it is the initial stage of the whole reaction.

Stage 4 is $593.90 \sim 654.02 \mathrm{~K}\left(320.75 \sim 380.87^{\circ} \mathrm{C}\right)$. It is the main reaction stage of thermal decomposition. It is generally believed that the test sample is internally restructured in this temperature range, producing mainly small molecule compounds and vaporizable macromolecules that exhibit significant weight losses. The relevant data are shown in Table 1.

Table 1. Related data of potato powder during thermal decomposition

\begin{tabular}{|c|c|c|c|c|c|c|c|}
\hline \multirow[b]{2}{*}{ Material } & \multicolumn{2}{|c|}{ First weight loss } & \multicolumn{2}{|c|}{ Second weight loss } & \multicolumn{2}{|c|}{ Third weight loss } & \multirow{2}{*}{$\begin{array}{r}\text { Residual } \\
\text { ash /mg }\end{array}$} \\
\hline & \begin{tabular}{|l|} 
TG loss of \\
weight $/ \%$
\end{tabular} & $\begin{array}{c}\text { DTG peak } \\
\text { temperature/K }\end{array}$ & $\begin{array}{l}\text { TG loss of } \\
\text { weight } / \% \\
\end{array}$ & $\begin{array}{c}\text { DTG peak } \\
\text { temperature /K }\end{array}$ & $\begin{array}{l}\text { TG loss of } \\
\text { weight } / \% \\
\end{array}$ & \begin{tabular}{|c|} 
DTG peak \\
temperature /K
\end{tabular} & \\
\hline $\begin{array}{l}\text { Potato } \\
\text { powder }\end{array}$ & 10.565 & 343.430 & 17.448 & 577.890 & 53.534 & 613.760 & 0.143 \\
\hline
\end{tabular}




\section{Determination of the thermal decomposition kinetic mechanism function}

The Coats-Redfern integration method has been widely used in thermal decomposition kinetics studies, as it can well reflect the mechanism of the thermal decomposition reaction. In the kinetic data processing, this paper also adopted this method to calculate the kinetic parameters and the kinetic equation for the thermal decomposition process of potato powder. The equation is derived as follows using the Coats-Redfern integration method (under nonisothermal conditions):

According to the mass equation, the reaction rate equation can be expressed as Equation 1:

$$
\frac{d \alpha}{d T}=k f(\alpha)
$$

where $\alpha$ is the conversion percentage, $\alpha=\frac{m_{0}-m}{m_{0}-m_{f}}$, also called the conversion rate; $m$ is the sample mass, $\mathrm{m}_{0}$ the initial reaction mass and $\mathrm{m}_{\mathrm{f}}$ the final reaction mass; $\mathrm{T}$ is the temperature; $\mathrm{k}$ is the constant of reaction rate; $\mathrm{f}(\alpha)$ is the differential form of the kinetic mechanism function.

The Arrhenius equation is Equation 2:

$$
K=A \exp \left(-\frac{E}{R T}\right)
$$

where $\mathrm{A}$ is the pre-exponential factor; $\mathrm{E}$ the activation energy, $\mathrm{J} / \mathrm{mol}$; $\mathrm{R}$ the molar gas constant, $8.314 \mathrm{~J} /(\mathrm{K} \cdot \mathrm{mol})$; and $\mathrm{T}$ the thermodynamic temperature.

Substitute Equation 2 into Equation 1, and we have Equation 3:

$$
\frac{d \alpha}{d T}=\frac{A}{\beta} \exp \left(-\frac{E}{R T}\right) f(\alpha)
$$

where $\beta$ is the heating rate.

Separate the variable, and we have Equation 4:

$$
\frac{d \alpha}{f(\alpha)}=\frac{A}{\beta} \exp \left(-\frac{E}{R T}\right) d T
$$

Integrate the two sides of the equation (Eq. 5):

$$
\int_{0}^{\alpha} \frac{d \alpha}{f(\alpha)}=\int_{0}^{T} \frac{A}{\beta} A \exp \left(-\frac{E}{R T}\right) d T
$$

Rearrange the integral Equation 5, and we have the coast-Redfield integral equation (Eq. 6):

$$
\ln \left[\frac{\mathrm{G}(\alpha)}{T^{2}}\right]=\ln \frac{A R}{\beta E}-\frac{E}{R T}
$$

Plot a graph with $\ln \left[\frac{G(\alpha)}{T^{2}}\right]$ as the $\mathrm{x}$-axis and $\frac{1}{T}$ as the $\mathrm{y}$-axis, and we can obtain a straight line, with a slope of $-\frac{E}{R}$ (if the $\mathrm{n}$ value is correct), and an intercept of $\ln \frac{A R}{\beta E}$. And then the $\mathrm{E}$ and A values can be calculated through the equation. 
In order to calculate the activation energy $\mathrm{E}$ and the pre-exponential factor $\mathrm{A}$ of the potato powder more accurately, the experimental data of four mechanism functions commonly used for the calculation of starch activation energy were listed below and compared to find out the linear regression equation with the best linear fit (Eqs. 7-10):

$$
\begin{gathered}
-\ln (1-\alpha)=\mathrm{G}(\alpha) \\
{[-\ln (1-\alpha)]^{\frac{\alpha}{\mathrm{s}}}=\mathrm{G}(\alpha)} \\
{[-\ln (1-\alpha)]^{\frac{1}{2}}=\mathrm{G}(\alpha)} \\
{[-\ln (1-\alpha)]^{\frac{1}{\mathrm{~s}}}=\mathrm{G}(\alpha)}
\end{gathered}
$$

(1) Kinetic analysis on the major stages of thermal decomposition of potato powder

The main stage of the thermal decomposition of potato powder is the main reaction stage as most of the changes in the material occur in this temperature range. Relevant kinetic data in the main stage of the thermal decomposition are listed in Table 2 (Yue et al., 2012).

Draw the scatter plot of $\ln \left[\frac{\mathrm{G}(\alpha)}{T^{2}}\right]$ and $\frac{1}{T}$, as shown in Figure 5.

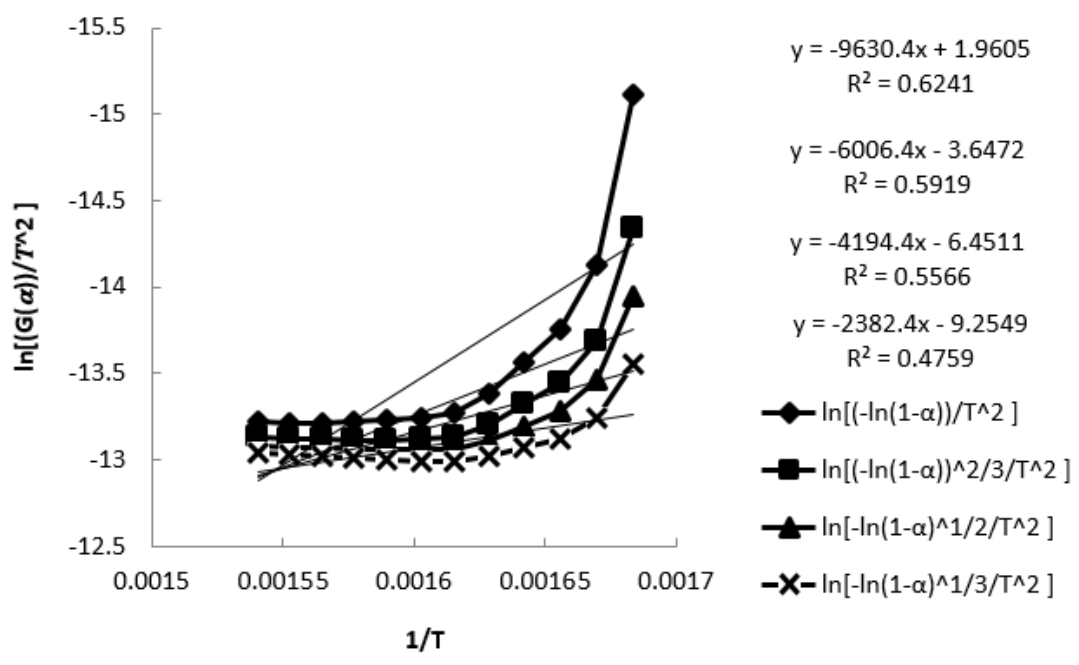

Figure 5. Scatter plot of $\ln \left[\frac{G(\alpha)}{T^{2}}\right]$ and $\frac{1}{T}$ in the main reaction stage

From the above four mechanism functions and the scatter plot of $\frac{1}{T}$, it can be seen that the linear regression equation has a low linear fit, so the main reaction stage does not conform to the first-order kinetic equation, which requires further discussion.

\section{(2) Kinetic analysis on the initial thermal decomposition stage of potato powder}

The initial stage of the thermal decomposition of potato powder, where the internal small-molecule substances of the potato begin to undergo thermal decomposition, marks 
the change of potato powder properties. The kinetic data of the thermal decomposition of potato powder at the initial stage are listed in Table 3.

Draw the scatter plot of $\ln \left[\frac{\mathrm{G}(\alpha)}{T^{2}}\right]$ and $\frac{1}{T}$, as shown in Figure 6.
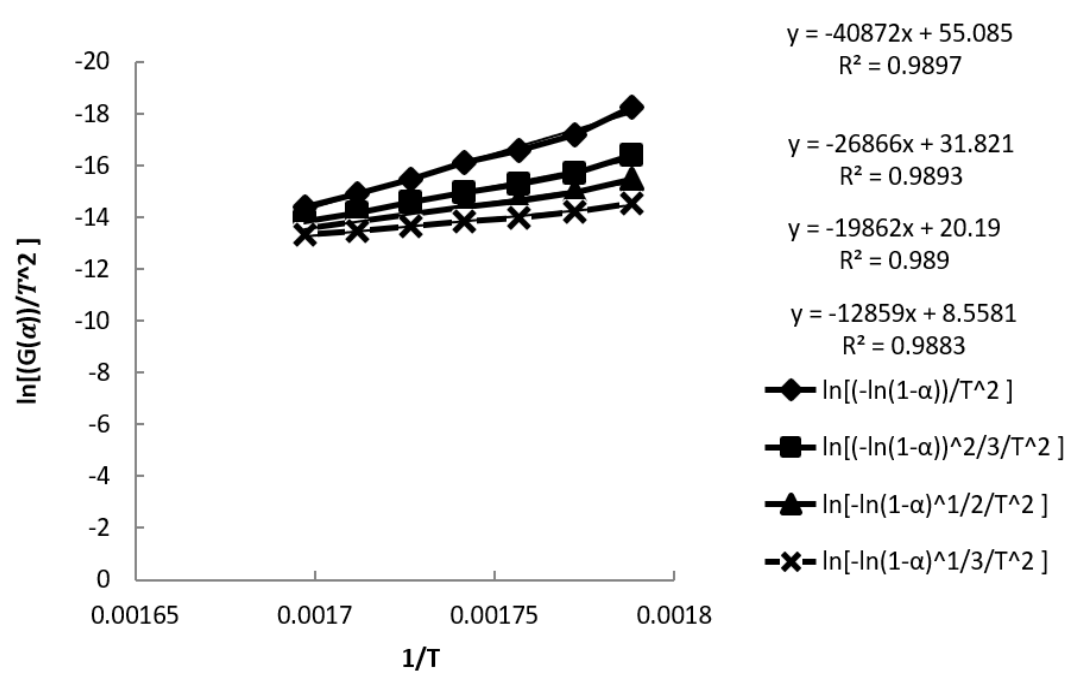

Figure 6. Scatter plot of $\ln \left[\frac{G(\alpha)}{T^{2}}\right]$ and $\frac{1}{T}$ in the initial reaction stage

From the above four mechanism functions and the scatter plot of $\frac{1}{T}$, it can be seen that, when $\mathrm{G}(\alpha)=-\ln (1-\alpha)$, the correlation coefficient is 0.9897 ; when $\mathrm{G}(\alpha)=[-\ln (1-\alpha)]^{\frac{2}{x}}$, it is 0.9893 ; when $\mathrm{G}(\alpha)=[-\ln (1-\alpha)]^{\frac{1}{2}}$, it is 0.989 ; when $\mathrm{G}(\alpha)=[-\ln (1-\alpha)]^{\frac{1}{x}}$, it is 0.9883 . So the linear regression equations obtained based on the above four mechanism functions all have a good linear fit and conform to the first-order kinetic equation. And when $\mathrm{G}(\alpha)=-\ln (1-\alpha)$, the linear fit is the best; in other words, if $\mathrm{G}(\alpha)=-\ln (1-\alpha)$ is adopted, the activation energy value $\mathrm{E}$ and the pre-exponential factor value A calculated will be closer to the true values.

Table 2. Kinetic data of the main thermal decomposition stage of potato powder

\begin{tabular}{l|c|c|c|c|c|c}
\hline \multirow{2}{*}{ Sample } & \multirow{2}{*}{ T/K } & \multirow{2}{*}{$\alpha / \%$} & \multicolumn{4}{|c}{$\ln \left[\frac{\mathrm{G}(\alpha)}{T^{2}}\right]$} \\
\cline { 4 - 7 } & & & Equation 7 & Equation 8 & Equation 9 & Equation 10 \\
\hline \multirow{5}{*}{ Potato powder } & 594.02 & 9.19 & -15.1132 & -14.3334 & -13.9435 & -13.5536 \\
& 599.02 & 23.03 & -14.1310 & -13.6842 & -13.4608 & -13.2374 \\
& 604.02 & 32.11 & -13.7560 & -13.4397 & -13.2816 & -13.1235 \\
& 609.02 & 37.91 & -13.5648 & -13.3178 & -13.1943 & -13.0707 \\
& 614.02 & 44.05 & -13.3836 & -13.2024 & -13.1118 & -13.0212 \\
& 619.02 & 48.33 & -13.2715 & -13.1331 & -13.0639 & -12.9947 \\
& 624.02 & 49.96 & -13.2399 & -13.1174 & -13.0562 & -12.9949 \\
& 629.02 & 50.97 & -13.2271 & -13.1141 & -13.0577 & -13.0012 \\
& 634.02 & 51.75 & -13.2206 & -13.1151 & -13.0624 & -13.0096 \\
& 639.02 & 52.46 & -13.2163 & -13.1175 & -13.0681 & -13.0187 \\
& 644.02 & 53.05 & -13.2150 & -13.1218 & -13.0752 & -13.0286 \\
& 649.02 & 53.53 & -13.2169 & -13.1283 & -13.0839 & -13.0396 \\
\hline
\end{tabular}


Table 3. Kinetic data of the initial thermal decomposition stage of potato powder

\begin{tabular}{l|c|c|c|c|c|c}
\hline \multirow{2}{*}{ Sample } & \multirow{2}{*}{ T/K } & \multirow{2}{*}{$\alpha / \%$} & \multicolumn{4}{|c}{$\ln \left[\frac{\mathrm{G}(\alpha)}{T^{2}}\right]$} \\
\cline { 4 - 7 } & & & Equation 7 & Equation 8 & Equation 9 & Equation 10 \\
\hline \multirow{5}{*}{ Potato powder } & 559.18 & 0.37 & -18.2451 & -16.3811 & -15.4490 & -14.5170 \\
& 564.18 & 1.08 & -17.1945 & -15.6866 & -14.9326 & -14.1787 \\
& 569.18 & 2.01 & -16.5858 & -15.2867 & -14.6370 & -13.9875 \\
& 574.18 & 3.31 & -16.0970 & -14.9666 & -14.4015 & -13.8363 \\
& 579.18 & 6.25 & -15.4637 & -14.5502 & -14.0934 & -13.6367 \\
& 584.18 & 11.16 & -14.8746 & -14.1632 & -13.8075 & -13.4518 \\
& 589.18 & 17.86 & -14.3835 & -13.8415 & -13.5705 & -13.2995 \\
\hline
\end{tabular}

\section{Determination of the thermal decomposition kinetic parameters and calculation of the kinetic equation}

Since the main reaction stage does not conform to the first-order kinetic equation, the following section only analyzes the initial stage of the entire reaction.

Since the main reaction stage does not conform to the first-order kinetic equation, the following section only analyzes the initial stage of the entire reaction.

Through the linear relation analysis of $\ln \left[\frac{-\ln (1-\alpha)}{T^{2}}\right]$ and $\frac{1}{T}$, it can be seen that the linear regression equation is $y=-40872 x+55.085$. By the Coats-Redfern integral method, it can be found that the slope is $-40872=-\frac{E}{R}$ and that the intercept $55.085=\ln \frac{A R}{\beta E}$. From $-\frac{E}{R}=-40872$, it can be concluded that the activation energy $\mathrm{E}=339.810 \mathrm{~kJ} / \mathrm{mol}$, and from $\ln \frac{A R}{\beta E}=55.085$, the pre-exponential factor can be obtained, which is $\mathrm{A}=\mathrm{e}^{75.32}$.

From $\mathrm{G}(\alpha)=-\ln (1-\alpha)=\int \frac{d \alpha}{f(\alpha)}$, it can be deduced that $f(\alpha)=1-\alpha$, so the kinetic equation for potato powder is: $\frac{\mathrm{d} \alpha}{\mathrm{dt}}=e^{75.32-\frac{889810}{8.814 T}}(1-\alpha)$.

\section{Conclusions}

(1) Under different sample masses and heating rates, the areas and time of the peaks in the thermograms of the potato powder are significantly different. Through condition tests, it is found that the optimal test conditions for the thermal decomposition of potato powder include a heating rate $\beta$ of $15^{\circ} \mathrm{C} / \mathrm{min}$ and a sample mass of $2.695 \mathrm{mg}$.

(2) Through the analysis of the thermal decomposition process of potato powder, it can be concluded that the weight loss of potato powder occurred in the temperature range of $316.68 \sim 425.11 \mathrm{~K}\left(43.53 \sim 151.96^{\circ} \mathrm{C}\right)$. When the temperature exceeded $559.18 \mathrm{~K}\left(286.03{ }^{\circ} \mathrm{C}\right)$, the potato powder started to experience thermal decomposition.

(3) Through the above analysis, it can be seen that, when $\mathrm{G}(\alpha)=-\ln (1-\alpha)$, i.e. when the Coats-Redfern integral equation is $\ln \left[\frac{-\ln (1-\alpha)}{T^{2}}\right]=\ln \frac{A R}{\beta E}-\frac{E}{R T}$, the activation energy value $\mathrm{E}$ and the pre-exponential factor value $\mathrm{A}$ obtained are the closest to reality. Through the above calculations, it can be found that the thermal decomposition kinetic parameters of potato powder are as follows: the activation energy $\mathrm{E}=339809.81 \mathrm{~J} / \mathrm{mol}$ 
$(339.81 \mathrm{KJ} / \mathrm{mol})$ and the pre-exponential factor $\mathrm{A}=\mathrm{e}^{75.32}$, and that the thermal decomposition kinetic equation $\frac{\mathrm{d} \alpha}{\mathrm{dt}}=e^{75.32-\frac{889810}{8.814 T}}(1-\alpha)$.

(4) In this paper, only differential thermal analysis method was used to study the pyrolysis kinetics of potato powder, but potato powder was also affected by many other factors in the processing process, so it can be further explored from the aspects of environmental humidity and $\mathrm{PH}$ of processing in the future.

Acknowledgements. Breeding and Promotion of New Specialized Potato Varieties for Staple Food in Panxi Area (Project No. 2016NYZ0032-4), National Modern Agricultural Industry Technology System Sichuan Potato Innovation Team (Sichuan Provincial Finance Education [2019] No. 59). Research on Key Brewing Techniques of Potato Liquor by Solid Fermentation, Academic Leader and Technology Leader Training Fund Project of Liangshan Prefecture, 2017. Key Brewing Technology of Potato Liquor by Solid Fermentation, Project of Sichuan Education Department, 17ZA0351. Research on Microbial Community During the Brewing Process of Potato Fermented Products: Taking Potato-Fermented Tartary Buckwheat Wine as an Example, Project of Sichuan Science and Technology Department, 2018JY0396.

\section{REFERENCES}

[1] Alonso, M., Borrego, A. G., Alvarez, D., Menéndez, R. (2001): A reactivity study of chars obtained at different temperatures in relation to their petrographic characteristics. Fuel Processing Technology 69(3): 257-272.

[2] Bao, H. H., Zhou, R., Liu, Y. L., Cao, L. K., Yang, Z. H. (2013): Development of green tea flavored potato whole powder cookies. - Academic Periodical of Farm Products Processing 9: 23-25.

[3] Chakraborty, S. (2015): Effect of potato powder supplementation and spices addition on physical and sensory properties of cookies. - International Journal of Research in Engineering and Technology 3(4): 408-416.

[4] Chen, L. T., Dong, Z. R., Huang, T. S. (2001): Application of differential thermal analysis in physical and chemical experiments. - Laboratory Research and Exploration 20(2): 96-98.

[5] Chen, Z. C. (2009): Development of potato whole flour bread. - Grain Science and Technology and Economy 3: 50-51.

[6] Fan, S. Q., Chen, S., Tang, X. Y., Xiao, Z. Y., Deng, P., Yao, P. N., Sun, Z. P., Zhang, Y., Chen, C. Y. (2015): Kinetic model of continuous ethanol fermentation in closedcirculating process with pervaporation membrane bioreactor by Saccharomyces cerevisiae. - Bioresource Technology 117(2): 169-175.

[7] Ghaly, A. E., Kamal, M., Correia, L. R. (2005): Kinetic modelling of continuous submerged fermentation of cheese whey for single cell protein production. - Bioresource Technology 96(10): 1143-1152.

[8] Huang, H. Y., Li, J. L., Liu, H. (2018): Thermal analysis kinetics of Tartary buckwheat flour. - International Journal of Heat and Technology 36(4): 1414-1422.

[9] Ike, C. C. (2018): Exponential fourier integral transform method for stress analysis of boundary load on soil. - Mathematical Modelling of Engineering Problems 5(1): 33-39.

[10] Kim, D., Ahn, S., Moon, C., Choi, G., Kim, T., Sung, Y. (2013): Effect of blending ratio on combustion performance in blends of biomass and coals of different ranks. Experimental Thermal and Fluid Science (47): 232-240.

[11] Liu, Z., Wu, Z., Li, R., Fan, X. (2013): Two-stage foam separation technology for recovering potato protein from potato processing wastewater using the column with the spiral internal component. - Journal of Food Engineering 114(02): 192-198. 
[12] Song, S. S., Wu, T. X. (2016): Study on degradation kinetics of Pitaya pigment. - Storage and Process 169(5): 74-79.

[13] Stenseng, M., Jensen, A., Dam-Johansen, K. (2001): Investigation of biomass pyrolysis by thermogravimetric analysis and differential scanning calorimetry. - Journal of Analytical and Applied Pyrolysis 58(1): 765-780.

[14] Wu, P., Zhu, H., Zhang, W., Zhao, F. Q., Yuan, C., Yin, C. M., Qiu, G. (2002): TG Characteristics of GAP Fuel-Rich Propellant and its Ingredients. - Energetic Materials 10(1): 18-20.

[15] Xie, Y. G. (2014): Accelerate the development of Liangshan Prefecture's characteristics and superior quality agricultural industry. - Resource Development \& Market (11): 13661370.

[16] Xu, Z., Wang, S. N., Zhao, D., Yang, P. (2017): Advances in preparation, properties and main food processing of potato whole flour. - Science and Technology of Food Industry 38(19): 322-326.

[17] Yue, J., Zhu, Z. C., Cao, H. (2012): Study on the basic characteristics of different varieties of potato powder. - Feed Research (10): 81-83.

[18] Zeng, D. Y., Xu, D., Liu, G. (2015): Potato nutrition review. - Chinese Potato Journal 29(4): 233-243.

[19] Zhang, K., Zhang, K., Cao, Y., Pan, W. (2013): Co-combustion characteristics and blending optimization of tobacco stem and high-sulfur bituminous coal based o-n thermogravimetric and mass spectrometry analyses. - BioresourcesTechnology 131: 325332.

[20] Zhao, J. W. (2005): Modern Food Testing Technology. - China Light Industry Press, Beijing. 